\title{
CLASSICAL CORNELIA DE LANGE SYNDROME
}

\author{
E.V. BADOE \\ Department of Child Health, University of Ghana Medical School, College of Health Sciences, P.O. \\ Box 4236, Accra, Ghana
}

\begin{abstract}
SUMMARY
These two case reports illustrate the importance of doing a thorough dysmorphology examination for all so called "Multiple congenital anomalies" children and attempting to fit them into a recognized syndrome. Well over 2000 dysmorphic syndromes are now recognized and diagnosis of these children can be extremely difficult.
\end{abstract}

Keywords: Cornelia de Lange syndrome, synophrys, long philtrum, distinctive facial features, malformation of limbs

\section{INTRODUCTION}

Cornelia de Lange (CDL) syndrome is a rare malformation syndrome with a birth incidence of approximately 1 in 40,000. Though named after Professor Cornelia de Lange it is sometimes called Brachman de Lange syndrome. Brachmann, a German doctor described an earlier case. It is now reckoned that a Dutch anatomist by name Vrolik described the first case in the $18^{\text {th }}$ century ${ }^{1}$.

The CDL syndrome is characterized by retardation of growth, learning difficulties, distinctive facial features, and abnormalities of limb development.

A group exists whose growth and development are less retarded than cases reported in the literature and are known as 'mild' rather than classical de Lange syndrome ${ }^{2}$.

The facial features are the most diagnostic and the following classic features are seen ${ }^{3}$ : confluent eyebrows (synophrys) (99\%), long curly eyelashes (99\%), short neck with low anterior and posterior hairlines (92\%), neat, well defined, and arched eyebrows as though they have been pencilled; long philtrum, anteverted nares (88\%) and underdeveloped orbital arches in $100 \%$ of cases. A downturned angle of the mouth is seen in $94 \%$ of cases. Hirsutism may be prominent and generalized.

In this article, we report two cases of Cornelia De Lange syndrome seen at the Paediatric department at Korle Bu Teaching Hospital (KBTH) over a two year period. The author is using these two cases to support the argument that genetics and for that matter dysmorphology training is an essential part of paediatrics.

\section{CASE 1}

A female infant two weeks old was referred to the Korle Bu Teaching Hospital in July 2002 on account of multiple congenital anomalies and regurgitation of feeds. She was born at 30 weeks gestation by emergency caesarean section due to pregnancy induced hypertension. Mother claimed not to be aware of the pregnancy and reported to hospital because of general malaise.

Examination findings were an acutely ill looking infant weighing $0.8 \mathrm{~kg}$ with a temperature of $35.7^{\circ}$ C. In addition the notes documented low set ears, bilateral absent radius and ulna, single digit over elbow area (bilateral). The sagittal sutures were open. The cardiovascular, respiratory and abdominal examinations were described as normal. The assessment was multiple congenital anomalies with sepsis. A nasogastric tube could not be passed and child was cup fed during her two week stay. She was managed on ampicillin, gentamycin and formula milk. The mother did not want to bond with the baby because of the anomalies and as such declined to breastfeed.

She made significant clinical improvement gaining weight up to $1.0 \mathrm{~kg}$. She was due to be discharged when she died suddenly two weeks after her admission (Figure 1).

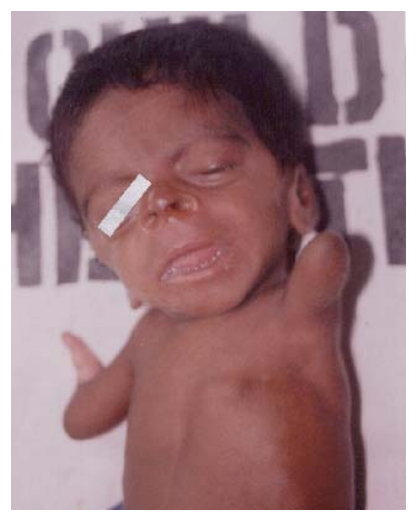

Figure 1 CDL with upturned nose, long philtrum and arched eye brows 


\section{CASE 2}

A female infant born on 17/11/04 was admitted to the Korle Bu Teaching Hospital, Children's department aged 2.5 months with a presenting complaint of stiffening of the limbs of a day's duration. She was apparently well before the stiffening episodes were noted. The mother had also noticed vomiting of milk feeds which she described as "forceful" but had accepted that as normal for the child.

In the antenatal period the mother developed antepartum haemorrhage at four months and vomiting at 7 months. The pregnancy was otherwise described as uneventful except for two occasions when she thought she contracted malaria and was treated with antimalarial medicines with good response.

The baby was born at 8.5 months at a private maternity home. The infant cried soon after birth and weighed $1.8 \mathrm{~kg}$. The mother noticed that the baby was very hairy all over.

She was the second child. Two weeks after birth infant developed a facial rash which initially was described as fluid filled but later developed into a large, raised, depigmented rash over the cheeks and eyebrows. The mother also confirmed that the child was not yet smiling.

Examination revealed a febrile infant (38.5 degrees celcius) with a weight of $2.1 \mathrm{~kg}$., length of $45.0 \mathrm{~cm}$ and a head circumference of $31.0 \mathrm{~cm}$. All these measurements were well below the $0.4 \%$ centile on relevant standardized charts. Scissoring of the legs was noted in addition to increased muscle tone in the limbs. Her cry was described as shrill and not sustained. The cardiovascular, respiratory and abdominal examinations were normal. There was fifth finger curving (clinodactaly) and the toes were always flexed. The external genitalia were normal and no gross limb deformities were observed. She was managed on parenteral antibiotics and clotrimazole gel for the presumed fungal skin lesion on her cheeks. She improved clinically and the skin lesion also started to repigment. She will be followed up at the Neuro-developmental Clinic.

\section{DISCUSSION}

The two cases exhibit the spectrum of features, in terms of severity, as seen in Cornelia de Lange syndrome.
The clues to the diagnosis in the two cases were the distinctive facial features and limb abnormalities and the severe limb deformities (Figure 2).

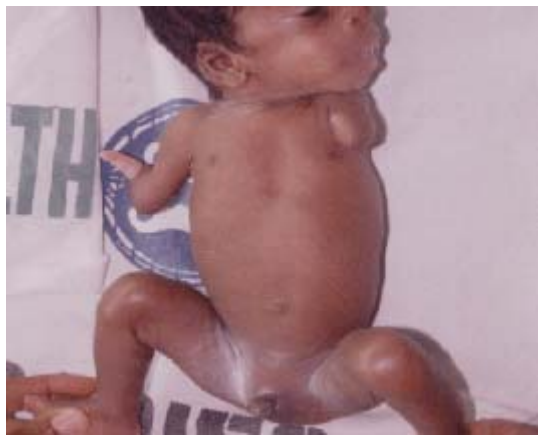

Figure 2 Classical CDL with severe limb abnormalities

The severe abnormalities in this case are bilateral but could have been unilateral. The most common abnormalities are short forearms and small hands with short metacarpals and short tapering fingers ${ }^{4}$.

Case 2 limb abnormalities - small hands and short tapering fingers. Note clinodactaly of fifth finger in both hands and the flexed nature of the fingers and toes (Figure 3).

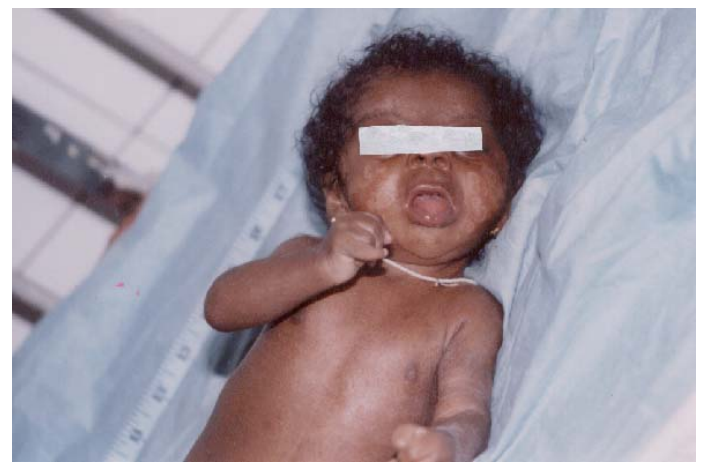

Figure 3 Mild CDL-Note clinodactaly and flexed fingers

\section{Facial features}

Both infants had small heads though a formal record in Case 1 was not documented despite stating it was micro-cephalic. In Case 1 the eyebrows can be appreciated to be neat, arched and long. The eyebrows tend to meet in the midline (synophrys) and this is better seen with age around 2 years. Other characteristics are a long philtrum (distance between nostrils and upper lip) down-turned angles of mouth as seen in Case 2, micrognathia and anteverted nostrils. The nasal bridge is also depressed. 
Both cases showed intrauterine growth retardation and this is a characteristic finding in the classical form of CDL syndrome. Average birth weight is $2.22 \mathrm{~kg}$ for males and $2.14 \mathrm{~kg}$ for females ${ }^{5}$. Severe learning difficulties (mental retardation) are noted in classical CDL syndrome. Speech is the most severely delayed area of development ${ }^{6}$.

The cases presented in this report also showed gastro-oesophageal reflux, a common complication of the syndrome, observed by the mothers as the child "pumps out her breastfeeds!". Reflux can be severe with complications such as stricture formation and Barrett's oesophagus being present at time of diagnosis ${ }^{7}$. Respiratory and feeding difficulties usually result in failure to thrive.

Most cases are sporadic resulting from new autosomal dominant mutation. Autosomal dominant transmission has been documented ${ }^{8}$. Heterozygous mutations in a gene named NIPBL, the human homolog of the Drosophilia Melanogaster Nipped$\mathrm{B}$ gene, have been identified in a group of individuals with CDL syndrome ${ }^{9,10}$.

In the absence of cardiac problems, diaphragmatic hernia or severe proximal truncation of the limbs, children with CDL can be expected to live to adulthood. A subgroup of infants with the classical phenotype are stillborn or die shortly after birth ${ }^{11}$.

\section{CONCLUSION}

Cornelia de Lange syndrome is a rare but well characterized syndrome. The key diagnostic features are the distinctive facial features, limb anomalies and growth retardation. It is hoped that with the report of these two cases at the Korle $\mathrm{Bu}$ Teaching hospital every attempt will be made to characterize "multiple congenital anomalies" that present to the hospital.

\section{REFERENCES}

1. Oostra RJ, Baljet B, Hennekam RCM. Brachmann-de Lange syndrome 'Avant la Lettre’. Am J Med Genet 1994; 52: 267-268

2. Ireland M, Donnai D, Burn J. Brachmann-de Lange syndrome. Delineation of the clinical phenotype. Am J Med Genet 1993; 47: 959964

3. Mustafa Tekin: Cornelia de Lange syndrome. www.emedicine.com/ped/topic482.htm.

(last updated Jan 3, 2006)

4. Ireland M. Cornelia de Lange syndrome: clinical features, common complications and long term prognosis. Curr Paediatr 1996; 6: 69-73

5. Kline AD, Barr M, Jackson LG. Growth manifestations in the Brachmann-de Lange syndrome. Am J Med Genet 1993; 47: 1042-1049

6. Goodban MT. Survey of speech and language skills with prognostic indicators in 116 patients with Cornelia de Lange syndrome. Am J Med Genet 1993; 47: 1059-1063

7. Bull MJ Fitzgerald JF, Heifetz SA, Brei TJ. Gastrointestinal abnormalities: A significant cause of feeding difficulties and failure to thrive in Brachman-de Lange syndrome. Am J Med Genet 1993; 47:1029-1034.

8. Kozma C. Autosomal dominant inheritance of Brachman-de Lange syndrome. Am J Med Genet 1996; 66: 445-448.

9. Krantz ID, McCallum J, DeSipio C, et al : Cornelia de Lange syndrome is caused by mutations in NIPBL,the human homolog of Drosophilia melanogaster Nipped-B. Nature Genet 2004; 36: 631-635

10. Gillis LA, McCallum J, Kaur M, et al. NIPBL mutational analysis in 120 individuals with Cornelia de Lange syndrome and evaluation of genotype-phenotype correlations. Am J Hum Genet 2004; 75: 610-623

11. Cunniff C, Curry CJR, Carey JC et al. Congenital diaphragmatic hernia in the Brachmande lange syndrome. Am J Med Genet 1993; 47: 1018-1021. 